\title{
Adsorption behaviour and surfactant elution of cationic salivary proteins at solid/liquid interfaces, studied by in situ ellipsometry
}

\author{
Ida E. Svendsen ${ }^{\mathrm{a}, \mathrm{b}, *}$, Liselott Lindh ${ }^{\mathrm{b}}$, Thomas Arnebrant ${ }^{\mathrm{b}}$ \\ ${ }^{a}$ Biomedical Laboratory Science, Faculty of Health and Society, Malmö University, SE-205 06 Malmö, Sweden \\ ${ }^{\mathrm{b}}$ Prosthetic Dentistry, Faculty of Odontology, Malmö University, SE-205 06 Malmö, Sweden
}

Received 15 May 2006; received in revised form 16 August 2006; accepted 23 August 2006

Available online 30 August 2006

\begin{abstract}
Adsorption of the cationic salivary proteins lactoferrin, lactoperoxidase, lysozyme and histatin 5 to pure (hydrophilic) and methylated (hydrophobized) silica surfaces was investigated by in situ ellipsometry. Effects of concentration $\left(\leq 10 \mu \mathrm{g} \mathrm{ml}^{-1}\right.$, for lysozyme $\left.\leq 200 \mu \mathrm{g} \mathrm{ml}{ }^{-1}\right)$ and dependence of surface wettability, as well as adsorption kinetics and elutability of adsorbed films by buffer and sodium dodecyl sulphate (SDS) solutions were investigated. Results showed that the amounts adsorbed decreased in the order lactoferrin $\geq$ lactoperoxidase $>$ lysozyme $\geq$ histatin 5 . On hydrophilic silica, the adsorption was most likely driven by electrostatic interactions, which resulted in adsorbed amounts of lactoferrin that indicated the formation of a monolayer with both side-on and end-on adsorbed molecules. For lactoperoxidase the adsorbed amounts were somewhat higher than an end-on monolayer, lysozyme adsorption showed amounts corresponding to a side-on monolayer, and histatin 5 displayed adsorbed amounts in the range of a side-on monolayer. On hydrophobized substrata, the adsorption was also mediated by hydrophobic interactions, which resulted in lower adsorbed amounts of lactoferrin and lactoperoxidase; closer to side-on monolayer coverage. For both lysozyme and histatin 5 the adsorbed amounts were the same as on the hydrophilic silica. The investigated proteins exhibited fast adsorption kinetics, and the initial kinetics indicated mass transport controlled behaviour at low concentrations on both types of substrates. Buffer rinsing and SDS elution indicated that the proteins in general were more tightly bound to the hydrophobized surface compared to hydrophilic silica. Overall, the surface activity of the investigated proteins implicates their importance in the salivary film formation.
\end{abstract}

(C) 2006 Elsevier B.V. All rights reserved.

Keywords: Lactoferrin; Lactoperoxidase; Lysozyme; Histatin 5; Pellicle

\section{Introduction}

When a clean surface is introduced in the oral environment it will quickly be covered by a thin film, composed mostly of constituents from saliva. This film, denoted pellicle [1], is formed by selective adsorption of mainly salivary proteins, among these proline-rich proteins, statherin, lysozyme, histatins and different types of glycoproteins. It is well accepted that the composition of this film influences the subsequent colonization of oral microbes on the oral surfaces (see e.g. [2] and references therein), which leads to the formation of dental plaque and, in some cases, further evolves into plaque related diseases such as caries and periodontitis. Lactoferrin, lactoperoxidase and lysozyme are examples of salivary proteins that are known to have protective

\footnotetext{
* Corresponding author. Tel.: +46 4066574 15; fax: +46 406658100 . E-mail address: Ida.Svendsen.HS@hs.mah.se (I.E. Svendsen).
}

functions, e.g. by decreasing the adherence and growth of hazardous microbes and thereby upholding a healthy ecosystem where pathogenic bacteria are suppressed (see e.g. review [3]). Lactoferrin and lactoperoxidase are both cationic glycoproteins with molecular weights of approximately $80 \mathrm{kDa}$, and isoelectric points $(\mathrm{p} I)$ around 9 (for reviews see [4-7]). The main antimicrobial function of lactoferrin is its iron-binding capacity which results in an indirect bacteriostatic effect, but it is also known to have bactericidal abilities not related to iron-binding $[5,6]$. It has been shown that the adsorption of lactoferrin to bacteria is associated with its bactericidal activities [5,6], indicating that the antimicrobial function is retained upon biological surfaces. Lactoperoxidase catalyses the oxidation of specific molecules by the aid of $\mathrm{H}_{2} \mathrm{O}_{2}$ to produce highly reactive products which have direct antimicrobial activity $[4,6]$. Lactoperoxidase has a high surface affinity and binds to different types of oral surfaces, upon which it retains its activity [6,7]. Lysozyme is a small protein $(14.5 \mathrm{kDa})$ with a pl of 11 and acts by e.g. aggregating 
bacteria, lysis of the peptidoglycan layer of bacteria cell walls and inhibiting bacterial adherence [6]. Studies have shown that lysozyme retains its activity when adsorbed in the pellicle [8].

Salivary peptides have also been shown to have antimicrobial activities. Histatins are a large family of small peptides with a high content of histidine and they are known to be both antibacterial and antifungal, inhibiting the growth of e.g. Candida albicans (see [9] and references therein). The most candidacidal peptide of this family has shown to be the cationic histatin 5 (3 kDa, $\mathrm{p} I=10)$ [9]. It has been suggested as a potential drug against oral candidiasis due to its potent antifungal activity against drug-resistant Candida strains and lack of toxicity to humans [9]. In vitro studies have shown that the candidacidal activity of histatin 5 is impaired when adsorbed to surfaces $[10,11]$, but upon desorption it is reactivated. Histatins have been identified in both in vitro and in vivo formed pellicles [12-14].

The overall character of the pellicle has been reported to be anionic [15]. Since cationic proteins like lactoferrin, lactoperoxidase, lysozyme and histatins have been identified in the pellicle it can be hypothesized that these antimicrobial proteins may enhance the protective functions of the pellicle. Furthermore, effects on the cohesiveness and thickness of the salivary film by electrostatic interactions with anionic pellicle proteins may also be anticipated. The formation of complexes between cationic salivary proteins and the large anionic mucins have been reported in several studies [16-18].

As a first step in understanding the role of cationic proteins in the pellicle build-up, and also their possible importance in complex formations with anionic components on surfaces, it was considered relevant to investigate the adsorption behaviour of the single proteins lactoferrin, lactoperoxidase, lysozyme and histatin 5. Due to availability reasons we chose to work with lactoferrin from human milk, lactoperoxidase from bovine milk, lysozyme from hen egg and synthetic histatin 5 . The experiments in the present study were carried out to investigate and compare the adsorption behaviour of these four proteins, under identical conditions, within the concentration ranges present in saliva (for lactoferrin and lactoperoxidase $\leq 10 \mu \mathrm{g} \mathrm{ml}^{-1}$ [6,7], lysozyme $\leq 200 \mu \mathrm{g} \mathrm{ml}^{-1}$ [6], and histatin $5 \leq 45 \mu \mathrm{g} \mathrm{ml}^{-1}$ [19]). Previously, studies have been performed on the adsorption of lactoferrin [20,21], lactoperoxidase [22] and lysozyme [20,23-27], however these publications were carried out using different techniques to some extent, and additionally they were not performed using the same concentration ranges, buffer solutions (or, to some extent, substrates) as the present investigation. The adsorption behaviour of the four chosen proteins was investigated on two types of silica surfaces with different characters. The influence of surface properties was included in this context. To the authors' knowledge, this is the first investigation on the adsorption of histatin 5 to silica surfaces.

Further, this study includes the investigation of elutability of adsorbed films by buffer and surfactant solutions, to characterize the interactions and the stability of the films. Surfactants such as SDS are common constituents in many oral care products (at concentrations up to $0.07 \mathrm{M}$ [28]) and it was therefore considered relevant to investigate the effect of SDS on the adsorbed protein films. In addition, as several of the proteins in the present investigation are known constituents of e.g. milk, protein-surfactant interactions are of importance in applications such as cleaning of food processing equipment.

The technique of null ellipsometry was employed for these studies, and it has previously been applied successfully for studies on protein adsorption ([29] and references therein). The general analysis of the experimental results obtained in the present investigation was primarily dealt with from a physico-chemical viewpoint, but also with input on the physiological context of the results (see section on significance).

\section{Experimental}

\subsection{Proteins}

Lactoferrin (L0520, 100\% pure), lactoperoxidase (L8257, $88 \%$ pure), and lysozyme (L6876, 95\% pure) were purchased from Sigma-Aldrich Sweden AB, (Stockholm, Sweden). Histatin 5 (72-2-25, >97\% pure) was obtained from American Peptide Company Inc. (Sunnyvale, CA, USA). All proteins were used as received. Values of the molecular dimensions of the proteins are shown in Table 1, including sited references. As different values of the dimensions of lactoferrin were found in recent literature, more than one dimension is given in Table 1. The results for lactoferrin were therefore analyzed considering the different dimensions given. The dimensions of histatin 5 are, to the authors' knowledge unknown. Studies have shown that it adopts random coil conformation in water and phosphate buffers [30]. The radius of gyration $\left(R_{\mathrm{g}}\right)$ was calculated (assuming a theta solvent), using the formula:

$R_{\mathrm{g}}^{2}=\frac{n l^{2}}{6}$

where $n$ is the number of amino acids (24 [9]), and $l$ is the length of each amino acid (approximated to $3.5 \AA$ [31]). A completely stretched molecule would then have a length of $84 \AA$.

Also presented in Table 1 are calculated amounts adsorbed corresponding to side-on and end-on monolayer, calculated from the formula:

$\Gamma=\frac{M_{\mathrm{w}}}{A N_{\mathrm{a}}}$

where $\Gamma$ is the amount protein per unit area $\left(\mathrm{mg} \mathrm{m}^{-2}\right), M_{\mathrm{w}}$ the molecular weight $\left(\mathrm{mg} \mathrm{mol}^{-1}\right), A$ the area per molecule $\left(\mathrm{m}^{2}\right)$, and $N_{\mathrm{a}}$ Avogadro's constant $\left(6.022 \times 10^{23} \mathrm{~mol}^{-1}\right)$. The proteins were considered to have a rectangular cross section, for histatin 5 the situation of hexagonally packed spheres with a cross section of $\pi R_{\mathrm{g}}^{2}$ was also considered.

\subsection{General}

The buffer solution (denoted PBS) was a $10 \mathrm{mM}$ phosphate buffer supplemented with $50 \mathrm{mM} \mathrm{NaCl}$, and adjusted to $\mathrm{pH} 7.0$. SDS (L6026, >99\% pure) used for the elution studies, was purchased from Sigma-Aldrich Sweden AB (Stockholm Sweden), and used as received. All water used was of ultra high quality 
Table 1

Some physico-chemical properties of the investigated proteins

\begin{tabular}{|c|c|c|c|c|}
\hline Dimensions $(\AA)$ & Monolayer $\left(\mathrm{mg} \mathrm{m}^{-2}\right)$ & Diffusion coefficient $\left(10^{-11} \mathrm{~m}^{2} \mathrm{~s}^{-1}\right)$ & Net charge at $\mathrm{pH} 7^{\mathrm{a}}$ & Aliphatic index ${ }^{b}$ \\
\hline \multicolumn{5}{|l|}{ Lactoferrin } \\
\hline $56 \times 95 \times 152^{\mathrm{c}}, 47 \times 47 \times 190^{\mathrm{d}}$ & $1.5-2.4^{\mathrm{e}}, 1.5-5.9^{\mathrm{e}}$ & $6.0^{\mathrm{f}}$ & +12 & 75 \\
\hline \multicolumn{5}{|l|}{ Lactoperoxidase } \\
\hline $55 \times 81 \times 78^{g}$ & $2.1-3^{\mathrm{e}}$ & $5.9^{\mathrm{h}}$ & +4 & 81 \\
\hline \multicolumn{5}{|l|}{ Lysozyme } \\
\hline $45 \times 30 \times 30^{\mathrm{i}}$ & $1.8-2.7^{\mathrm{e}}$ & $10.4^{\mathrm{j}}$ & +8 & 65 \\
\hline \multicolumn{5}{|l|}{ Histatin 5} \\
\hline$R_{\mathrm{g}}=7 \AA^{\mathrm{f}}, 7 \times 7 \times 84^{\mathrm{f}}($ stretched $)$ & $3,0.9-10.3^{\mathrm{e}}$ & $16^{\mathrm{f}}$ & +5 & 4 \\
\hline
\end{tabular}

a Theoretical charge calculated from the number of positively charged amino acid residues (arginin and lysine) minus the number of negatively charged amino acid residues (aspartic acid and glutamic acid).

${ }^{b}$ The relative volume occupied by aliphatic side chains. Values of net charge and aliphatic index were obtained from the Swiss-Prot database provided by The Swiss Institute of Bioinformatics.

${ }^{c}$ Data from X-ray diffraction (RCSB Protein Data Bank 1CB6).

d Data from Small Angle Neutron Scattering (SANS) [21].

Side-on-end-on.

${ }^{\mathrm{f}}$ Estimated as described in materials and methods.

g Data from X-ray diffraction (RCSB Protein Data Bank 2GJ1).

${ }^{h}$ Ref. [50].

${ }^{i}$ Ref. [49].

${ }^{j}$ Ref. [51].

(UHQ), processed in Elgastat UHQ II Model UHQ-PS-MK3 (Elga Ltd., High Wycombe, Bucks, England), and all chemicals used were of at least analytical grade (VWR International, Stockholm, Sweden).

\subsection{Solid surfaces}

The silicon wafers (P-type, boron doped, resistivity $10-20 \Omega \mathrm{cm}$ ) (Okmetic, Espoo, Finland) used for the ellipsometric experiments, were oxidized to an oxide thickness of approximately $30 \mathrm{~nm}$ [32] and cut into pieces measuring $10 \mathrm{~mm} \times 30 \mathrm{~mm}$. To obtain hydrophilic and hydrophobized (methylated) silica surfaces, the surfaces were treated as previously described [33-35]. Before use, substrates were rinsed with water, ethanol and water and the hydrophilic surfaces were also plasma cleaned in a Harrick Plasma Cleaner PDC-32G (Harrick Scientific Corporation, Ossining, NY, USA). Surfaces prepared as described above have been thoroughly characterized with respect to surface charge ( $\zeta$-potential of $-45 \mathrm{mV}$ for both pure and methylated silica) and water contact angle $\left(<10^{\circ}\right.$ for hydrophilic, and $\geq 90^{\circ}$ for hydrophobized substrates) [35].

\subsection{Null ellipsometry}

In situ null ellipsometry was used for studies of adsorption/elution at the solid/liquid interface. The technique has been described in detail previously [36]. The instrument used was a Rudolph thin film ellipsometer type 43603-200E (Rudolph Research, Fairfield, NJ, USA), automated according to Cuypers et al. [37]. The light source was a xenon lamp, filtered to $\lambda=442.9 \mathrm{~nm}$. The surface was mounted vertically in the ellipsometric cuvette containing $5 \mathrm{ml}$ of PBS buffer. The cuvette was kept at constant temperature $\left(37^{\circ} \mathrm{C}\right)$ and with a magnetic stirrer at constant stirring rate $(325 \mathrm{rpm})$. Before each measurement, a two-zone surface calibration, in two ambient media (air and PBS) was carried out. This was performed to determine the optical parameters of the substrate, i.e. the refractive index and thickness of the oxide layer. When a constant baseline was obtained, stock solutions of each respective protein was added to the cuvette to final concentrations of up to $10 \mu \mathrm{g} \mathrm{ml}^{-1}$ for lactoferrin, lactoperoxidase and histatin 5, and up to $200 \mu \mathrm{g} \mathrm{ml}^{-1}$ for lysozyme. The adsorption was measured for $120 \mathrm{~min}$, after which 5 min of rinsing with PBS was performed at a continuous flow of $15 \mathrm{ml} \mathrm{min}^{-1}$. After rinsing, the experiments were monitored for $30 \mathrm{~min}$, followed by addition of SDS solution $(17 \mathrm{mM}$ in the cuvette; approximately $8.7 \times$ critical micelle concentration (cmc) in buffer [38]). After $5 \mathrm{~min}$, another PBS rinsing was carried out as outlined above. The measurements were terminated after $30 \mathrm{~min}$ of final monitoring. Each experiment was carried out in at least duplicate.

\subsection{Mass transport analysis}

To investigate if the initial adsorption of each protein was mass transport controlled, the Trurnit model was employed [39]. This model applies to a stirred system, where the mass transport from the bulk to the solid/liquid interface is determined by diffusion over an unstirred layer closest to the solid surface. In the present study, the thickness of this unstirred layer was determined to be approximately $20 \mu \mathrm{m}$ [40]. The model further relies on the hypothesis that the adsorption is considered irreversible and that the time to create a constant concentration gradient in the unstirred layer is negligible. Under these conditions, the initial adsorption rates for a diffusion-controlled system are:

$\frac{\mathrm{d} \Gamma}{\mathrm{d} t}=\frac{D C_{0}}{\delta}$ 
Integration of this formula gives the amount adsorbed versus time:

$\Gamma=\frac{D C_{0} t}{\delta}$

where $\Gamma$ is the amount of adsorbed protein per unit area $\left(\mathrm{mg} \mathrm{m}^{-2}\right), D$ the diffusion coefficient $\left(\mathrm{m}^{2} \mathrm{~s}^{-1}\right), C_{0}$ the bulk concentration $\left(\mathrm{mg} \mathrm{m}^{-3}\right), \delta$ the thickness of the unstirred layer $(\mathrm{m})$ and $t$ is the time (s). The diffusion coefficients for the proteins are given in Table 1. For lactoferrin and histatin 5, the diffusion coefficients are, to the authors' knowledge, unknown. $D$ for lactoferrin was approximated to $6 \times 10^{-11} \mathrm{~m}^{2} \mathrm{~s}^{-1}$, close to that of lactoperoxidase, due to similar size and the fact that both proteins are globular. For histatin $5, D$ was estimated to be about $16 \times 10^{-11} \mathrm{~m}^{2} \mathrm{~s}^{-1}$ from a graph constructed of known diffusion coefficients versus molecular weights of a series of well-defined proteins as described in Lindh et al. [41]. Most of the proteins in this plot have globular structures, which might result in an overestimated value of the diffusion coefficient of histatin 5.

\section{Results and discussion}

The present study on the adsorption behaviour of cationic salivary proteins was performed to obtain information on these proteins in terms of (i) surface activity within their concentration range present in saliva, (ii) influence of surface characteristics, (iii) interaction with surface active components (SDS), and (iv) significance of adsorption in the oral cavity.

The results show the different film forming properties and elutabilities of lactoferrin, lactoperoxidase, lysozyme and histatin 5 on hydrophilic and hydrophobized silica substrates. These two model surfaces represent high and low surface energy substrates, and thereby span over the wide variety of hydrophobicity of different types of oral surfaces, both natural and artificial ones. The tooth enamel has a contact angle of $40^{\circ}$ [42] and a slight negative charge [43], and therefore its wettability will be between that of the two model surfaces used in the present study, but with a lower charge. The buffer solution was chosen to mimic the $\mathrm{pH}$ and ionic strength of saliva.

\subsection{Adsorbed amounts}

As can be seen in Fig. 1 and Table 2, the adsorption of lactoferrin was higher on hydrophilic silica than on hydrophobized surfaces, and the slopes of the isotherms showed that lactoferrin had a higher affinity for the hydrophilic silica. This indicates that the main driving force for adsorption is electrostatic attraction between positively charged segments of the protein and the negatively charged hydrophilic silica. These findings are supported by previous adsorption data on lactoferrin performed at higher concentrations [20], where it was shown that an increase in salt concentration resulted in a decrease in the adsorbed amounts, further supporting the indications of the importance of electrostatic driving forces for adsorption. Further, adsorption of lactoferrin was concentration dependent $\leq 5 \mu \mathrm{g} \mathrm{ml}^{-1}$ on both types of surfaces. The adsorbed amounts $\geq 5 \mu \mathrm{g} \mathrm{ml}^{-1}$ on hydrophilic silica $\left(3.7-4 \mathrm{mg} \mathrm{m}^{-2}\right)$ are in good agreement with those performed previously, at concentrations of 0.5 and $5 \mathrm{mg} \mathrm{ml}^{-1}\left(\sim 4 \mathrm{mg} \mathrm{m}^{-2}\right)$ [20] which indicates that a concentration of $5 \mu \mathrm{g} \mathrm{ml}^{-1}$ seems to be sufficient to reach an adsorption saturation for the investigated system. On hydrophobized surfaces, the adsorbed amounts at concentrations $>5 \mu \mathrm{g} \mathrm{ml}^{-1}\left(\sim 2.4 \mathrm{mg} \mathrm{m}^{-2}\right)$ was lower compared to the amounts adsorbed at 0.5 and $5 \mathrm{mg} \mathrm{m}^{-1}$ found in previous studies $\left(\sim 3.4 \mathrm{mg} \mathrm{m}^{-2}\right.$ ) [20], indicating that the plateau seen in Fig. $1 \mathrm{~b}$ is probably only a semi-plateau.

Comparing the adsorbed amounts of lactoferrin with calculated values for monolayer coverage (Tables 1 and 2) indicated that side-on monolayer was reached at concentrations as low as approximately $1 \mu \mathrm{g} \mathrm{ml}^{-1}$ and $2.5 \mu \mathrm{g} \mathrm{ml}^{-1}$ on hydrophilic and hydrophobized substrata, respectively. Considering the $3 \mathrm{D}$ crystalline structure of lactoferrin obtained by X-ray diffraction $(56 \AA \times 95 \AA \times 152 \AA$, see Table 1), amounts corresponding to a bilayer was adsorbed at the highest concentrations on

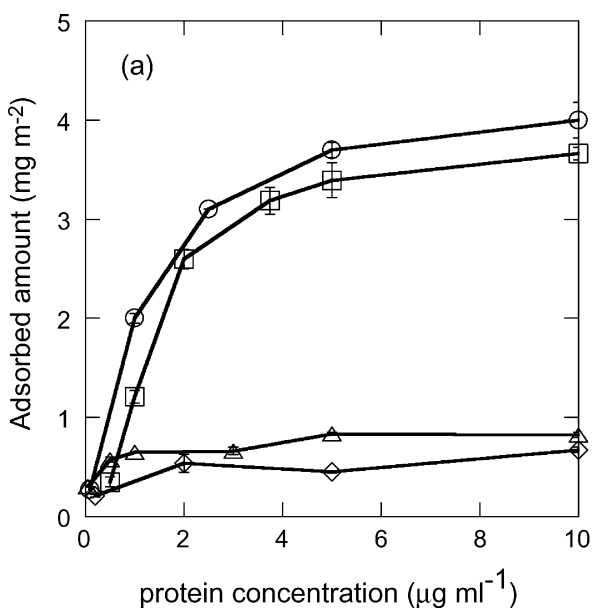

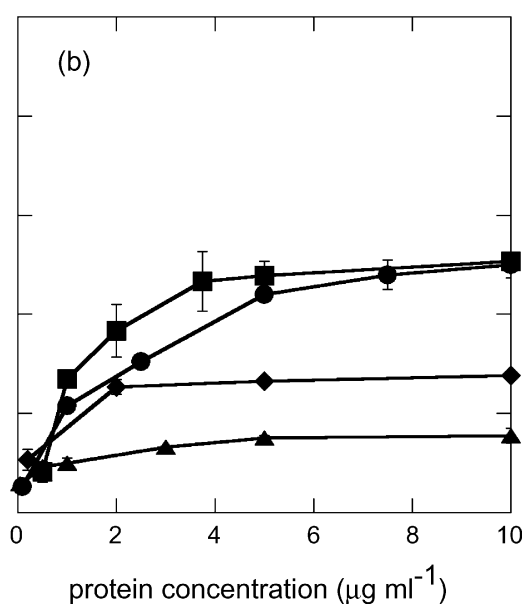

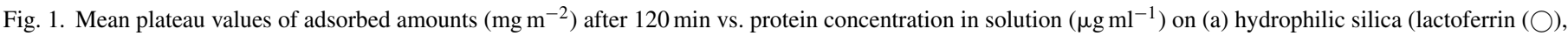

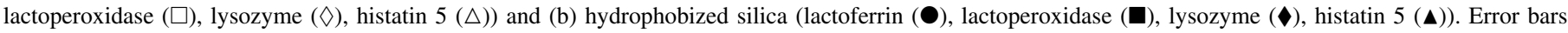
indicate standard deviation where $n>2$, and deviation from the mean where $n=2$ (see Table 2). 
Table 2

Mean adsorbed amounts after $120 \mathrm{~min}$ of adsorption, after PBS rinse, and after addition of $17 \mathrm{mM}$ SDS solution/PBS rinse, measured with ellipsometry

\begin{tabular}{|c|c|c|c|c|c|c|}
\hline \multirow{2}{*}{$\begin{array}{l}\text { Protein concentration } \\
\text { in solution }\left(\mu \mathrm{g} \mathrm{ml}^{-1}\right)\end{array}$} & \multicolumn{3}{|l|}{ Hydrophilic silica } & \multicolumn{3}{|l|}{ Hydrophobized silica } \\
\hline & $\begin{array}{l}\text { After } 120 \mathrm{~min} \text { of } \\
\text { adsorption }\left(\mathrm{mg} \mathrm{m}^{-2}\right)\end{array}$ & $\begin{array}{l}\text { After PBS rinse } \\
\left(\mathrm{mg} \mathrm{m}^{-2}\right)\end{array}$ & $\begin{array}{l}\text { After SDS/PBS rinse } \\
\left(\mathrm{mg} \mathrm{m}^{-2}\right)\end{array}$ & $\begin{array}{l}\text { After } 120 \mathrm{~min} \text { of } \\
\text { adsorption }\left(\mathrm{mg} \mathrm{m}^{-2}\right)\end{array}$ & $\begin{array}{l}\text { After PBS rinse } \\
\left(\mathrm{mg} \mathrm{m}^{-2}\right)\end{array}$ & $\begin{array}{l}\text { After SDS/PBS rinse } \\
\left(\mathrm{mg} \mathrm{m}^{-2}\right)\end{array}$ \\
\hline \multicolumn{7}{|l|}{ Lactoferrin } \\
\hline 10 & 4.0 S.D. 0.18 & 3.7 S.D. 0.18 & 0.3 S.D. $0.04(n=3)$ & 2.5 S.D. 0.13 & 2.5 S.D. 0.15 & 1.2 S.D. $0.17(n=5)$ \\
\hline 7.5 & & & & 2.4 S.D. 0.15 & 2.3 S.D. 0.13 & 1.1 S.D. $0.34(n=3)$ \\
\hline 5 & $3.7 \pm 0.08$ & $3.5 \pm 0.08$ & $0.3 \pm 0.00^{*}$ & $2.2 \pm 0.00$ & $2.1 \pm 0.03$ & $1.3 \pm 0.03^{*}$ \\
\hline 2.5 & $3.1 \pm 0.00$ & $3.1 \pm 0.00$ & $0.3 \pm 0.01^{*}$ & 1.5 S.D. 0.03 & 1.5 S.D. 0.03 & 1.1 S.D. $0.17(n=3)$ \\
\hline 1 & $2.0 \pm 0.05$ & $2.0 \pm 0.05$ & $0.3 \pm 0.04^{*}$ & $1.1 \pm 0.03$ & $1.1 \pm 0.00$ & $0.9 \pm 0.00^{*}$ \\
\hline 0.1 & $0.3 \pm 0.04$ & $0.3 \pm 0.04$ & $0.3 \pm 0.03^{*}$ & $0.3 \pm 0.04$ & $0.3 \pm 0.04$ & $0.2 \pm 0.04^{*}$ \\
\hline \multicolumn{7}{|l|}{ Lactoperoxidase } \\
\hline 10 & $3.7 \pm 0.06$ & $3.2 \pm 0.01$ & $0.4 \pm 0.05^{*}$ & $2.5 \pm 0.01$ & $2.5 \pm 0.00$ & $1.6 \pm 0.06^{*}$ \\
\hline 5 & 3.4 S.D. 0.18 & 3.2 S.D. 0.18 & 0.3 S.D. $0.30(n=3)$ & 2.4 S.D. 0.14 & 2.4 S.D. 0.12 & 1.4 S.D. $0.08(n=3)$ \\
\hline 3.75 & $3.2 \pm 0.14$ & $3.0 \pm 0.18$ & $0.4 \pm 0.03^{*}$ & 2.3 S.D. 0.30 & 2.2 S.D. 0.21 & 1.2 S.D. $0.05(n=3)$ \\
\hline 2 & $2.6 \pm 0.10$ & $2.6 \pm 0.10$ & $0.3 \pm 0.04^{*}$ & 1.8 S.D. 0.27 & 1.8 S.D. 0.25 & 1.0 S.D. $0.21(n=4)$ \\
\hline 1 & $1.2 \pm 0.06$ & $1.2 \pm 0.05$ & $0.3 \pm 0.05^{*}$ & $1.4 \pm 0.00$ & $1.4 \pm 0.00$ & $0.9 \pm 0.01^{*}$ \\
\hline 0.5 & 0.4 S.D. 0.05 & 0.4 S.D. 0.05 & 0.2 S.D. $0.06(n=3)$ & 0.4 S.D. 0.10 & 0.4 S.D. 0.12 & 0.3 S.D. $0.12(n=4)$ \\
\hline \multicolumn{7}{|l|}{ Lysozyme } \\
\hline 200 & $1.7 \pm 0.01$ & $0.9 \pm 0.03$ & $0.1 \pm 0.10^{*}$ & $1.7 \pm 0.05$ & $1.6 \pm 0.06$ & $0.6 \pm 0.05^{*}$ \\
\hline 100 & $1.7 \pm 0.01$ & $0.9 \pm 0.00$ & $0.3 \pm 0.03^{*}$ & $1.7 \pm 0.03$ & $1.7 \pm 0.01$ & $0.7 \pm 0.01^{*}$ \\
\hline 50 & $1.2 \pm 0.01$ & $0.5 \pm 0.03$ & $0.3 \pm 0.01^{*}$ & 1.4 S.D. 0.03 & 1.4 S.D. 0.04 & 0.4 S.D. $0.04(n=3)$ \\
\hline 10 & $0.7 \pm 0.03$ & $0.3 \pm 0.03$ & $0.2 \pm 0.04^{*}$ & 1.4 S.D. 0.03 & 1.4 S.D. 0.01 & 0.6 S.D. $0.06(n=3)$ \\
\hline 5 & $0.5 \pm 0.01$ & $0.3 \pm 0.03$ & $0.3 \pm 0.00^{*}$ & $1.3 \pm 0.03$ & $1.3 \pm 0.03$ & $0.3 \pm 0.03^{*}$ \\
\hline 2 & 0.5 S.D. 0.09 & 0.3 S.D. 0.09 & 0.3 S.D. $0.02(n=4)$ & 1.3 S.D. 0.08 & 1.3 S.D. 0.07 & 0.5 S.D. $0.10(n=3)$ \\
\hline 0.2 & $0.2 \pm 0.01$ & $0.3 \pm 0.00$ & $0.3 \pm 0.01^{*}$ & 0.5 S.D. 0.10 & 0.5 S.D. 0.11 & 0.5 S.D. $0.04(n=3)$ \\
\hline \multicolumn{7}{|l|}{ Histatin 5} \\
\hline 10 & $0.8 \pm 0.03$ & $0.6 \pm 0.01$ & $0.3 \pm 0.00^{*}$ & $0.8 \pm 0.08$ & $0.5 \pm 0.05$ & $0.3 \pm 0.05^{*}$ \\
\hline 5 & $0.8 \pm 0.01$ & $0.6 \pm 0.00$ & $0.3 \pm 0.01^{*}$ & $0.8 \pm 0.03$ & $0.4 \pm 0.04$ & $0.3 \pm 0.01^{*}$ \\
\hline 3 & $0.7 \pm 0.04$ & $0.4 \pm 0.04$ & $0.3 \pm 0.04^{*}$ & $0.7 \pm 0.01$ & $0.4 \pm 0.00$ & $0.3 \pm 0.01^{*}$ \\
\hline 1 & $0.7 \pm 0.00$ & $0.5 \pm 0.01$ & $0.3 \pm 0.03^{*}$ & $0.5 \pm 0.05$ & $0.3 \pm 0.01$ & $0.3 \pm 0.01^{*}$ \\
\hline 0.5 & $0.6 \pm 0.03$ & $0.5 \pm 0.03$ & $0.3 \pm 0.04^{*}$ & $0.5 \pm 0.01$ & $0.4 \pm 0.03$ & $0.3 \pm 0.00^{*}$ \\
\hline 0.05 & $0.3 \pm 0.00$ & $0.3 \pm 0.00$ & $0.3 \pm 0.01^{*}$ & $0.3 \pm 0.04$ & $0.3 \pm 0.01$ & $0.2 \pm 0.03^{*}$ \\
\hline
\end{tabular}

Numbers of repeated measurements for each concentration are given within parenthesis in the columns of SDS/PBS rinse. *Deviation from the mean where $n=2$. For $n>2$ the standard deviations are calculated.

a Value taken $30 \mathrm{~min}$ after end of rinse.

hydrophilic substrates, whereas on hydrophobized surfaces the adsorbed amount was in the range of an end-on monolayer (Table 2). However, the dimensions obtained by Small Angle Neutron Scattering (SANS; $47 \AA \times 47 \AA \times 190 \AA$, Table 1) indicated that a mixed monolayer composed of both side-on and end-on adsorbed molecules, or possibly a tilted end-on layer, was formed at the higher concentrations on both types of surfaces. The experiments using SANS [21] where performed in a phosphate buffer, similar to the one used in the present investigation, and these data therefore seem to be the most reliable for comparison.

Lactoperoxidase showed similar adsorbed amounts on both types of surfaces at concentrations $\leq 1 \mu \mathrm{g} \mathrm{ml}^{-1}$, while at higher concentrations the adsorbed amounts on hydrophilic substrata increased above that on the hydrophobized silica (Fig. 1 and Table 2). This indicates that electrostatic interactions are of great importance for lactoperoxidase adsorption. Lactoperoxidase, however, has a slightly higher affinity for hydrophobized surfaces than lactoferrin (deduced from the slopes of the isotherms in Fig. 1). Therefore also hydrophobic interactions may be anticipated to contribute to the adsorption. This is in agreement with the fact that lactoperoxidase has a lower charge at $\mathrm{pH} 7$ and a slightly higher aliphatic index but similar size and $\mathrm{p} I$ compared to lactoferrin, as seen in Table 1. The influence of the individual interactions could be clarified by e.g. studies at different ionic strengths. The isotherms of lactoperoxidase levelled off at concentrations $>4 \mu \mathrm{g} \mathrm{ml}^{-1}$ on both hydrophilic and methylated surfaces. Mårtensson et al. [22] investigated the adsorption of lactoperoxidase in $10 \mathrm{mM}$ phosphate buffer, and showed that the adsorbed amounts were concentration dependent below $1 \mu \mathrm{g} \mathrm{ml}^{-1}$ on both hydrophilic and hydrophobized silica. These data differs from the ones obtained here, and this may be explained by the higher ionic strength used in the present study that screens the electrostatic attraction between proteins and surfaces resulting in a shift of the isotherm towards higher concentrations. In addition, Mårtensson et al. [22] performed the adsorption experiments after the ellipsometric cuvette walls had been saturated with adsorption of lactoperoxidase. This factor also contributes to the differences in results compared to the data obtained in the present study.

On hydrophilic silica, the adsorption of lactoperoxidase reached amounts corresponding to side-on monolayer at concen- 
trations between $1-2 \mu \mathrm{g} \mathrm{ml}^{-1}$ and $>3.5 \mu \mathrm{g} \mathrm{ml}^{-1}$ the adsorbed amounts were higher than an end-on monolayer, indicating that a bilayer was starting to form. On hydrophobized surfaces, adsorbed amounts in the range of side-on monolayer was reached at concentrations $>2 \mu \mathrm{g} \mathrm{ml}^{-1}$. At higher concentrations, the adsorbed amounts corresponded to a mixture of side-on and end-on adsorbed molecules.

At low concentrations of lysozyme, the adsorbed amounts were lower on hydrophilic substrates than on hydrophobized silica (Fig. 1 and Table 2). At higher concentrations however $\left(\geq 100 \mu \mathrm{g} \mathrm{ml}^{-1}\right)$, the adsorbed amounts on the two types of substrates were the same (Table 2). The slopes of the isotherms indicated a higher affinity for the methylated silica. The adsorbed amounts on hydrophilic silica correlates well with previously reported values $[24,25]$. Adsorption at concentrations $\leq 0.2 \mathrm{mg} \mathrm{ml}^{-1}$ has, to the authors' knowledge, not been performed on methylated silica previously, using ellipsometry. Neutron reflectivity investigations [26] showed adsorbed amounts from $30 \mu \mathrm{g} \mathrm{ml}^{-1}$ to be $1.4 \mathrm{mg} \mathrm{m}^{-2}$ on octadecyltrichlorosilane modified silica, which is in good agreement with the data obtained here (Table 2). On both types of surfaces, the adsorbed amounts at higher concentrations $\left(\geq 100 \mu \mathrm{g} \mathrm{ml}^{-1}\right.$, see Table 2) showed excellent agreement with the calculated side-on monolayer (Table 1).

Similar adsorbed amounts of histatin 5 were observed on the two types of substrates (Fig. 1 and Table 2). Histatin 5 has 2 hydrophobic amino acids, and 6 polar, 2 negatively charged and 14 positively charged ones (including histidine). Due to the low hydrophobicity (also illustrated by the low aliphatic index in Table 1) and the dominance of positively charged amino acids histatin $5 \mathrm{can}$, in contradiction to the other proteins investigated, be regarded as a small polyelectrolyte. As both the hydrophilic and hydrophobized silica have a negative charge ( $\zeta$-potential of $-45 \mathrm{mV}$ ), the adsorption is likely driven by electrostatic interactions on both types of substrates.

The adsorption of histatin 5 was only concentration dependent at low concentrations $\left(\leq 1 \mu \mathrm{g} \mathrm{ml}^{-1}\right.$ on hydrophilic silica and $\leq 3 \mu \mathrm{g} \mathrm{ml}^{-1}$ on hydrophobized substrata), and we therefore chose to only investigate concentrations $\leq 10 \mu \mathrm{g} \mathrm{ml}^{-1}$, although histatin 5 is known to be present in saliva at concentrations of up to $45 \mu \mathrm{g} \mathrm{ml}^{-1}$ [19]. The amount of histatin 5 on the surfaces corresponded to a monolayer of completely stretched molecules (Tables 1 and 2). The above indications that histatin 5 can be considered as a polyelectrolyte support the stretched conformation on the surfaces. On the other hand, studies have shown that histatin 5 adopts random coil conformation in aqueous solutions [30]. Our data indicates that if such structures are present at the interface the density has to be far below monolayer coverage.

\subsection{Kinetics}

As representative examples of kinetics, adsorbed amounts versus time, upon adsorption from $10 \mu \mathrm{g} \mathrm{ml}^{-1}$ solutions of lactoferrin, lactoperoxidase, lysozyme and histatin 5, respectively, are illustrated on both types of substrates in Fig. 2. The fast adsorp- tion kinetics observed for all investigated proteins are supported by previous reports $[11,20,22,24]$. Histatin 5 adsorption to silica surfaces has, as pointed out above, not been investigated before. The adsorption of histatin 5 to hydroxyapatite (the main mineral component of enamel) showed fast kinetics, where a plateau was reached within a few minutes [11].

An overshoot in adsorption of lactoperoxidase was observed on hydrophobized surfaces (Fig. 2b), at concentrations $\geq 2 \mu \mathrm{g} \mathrm{ml}^{-1}$, and explanations may be orientational changes and/or competitive spreading. Unfolding/conformational changes of proteins adsorbed during the initial stages may take place, to increase their surface contact points and thus the molecules will be more strongly attached to the surface. This may result in decreased adsorbed amounts due to desorption of some of the more loosely adsorbed molecules. Another possible explanation may be competitive adsorption of different isoforms. Lactoperoxidase is known to consist of isoforms which have different $\mathrm{p} I$ 's $[4,6,7]$. A possible mechanism could be that one isoform present in highest concentration adsorbs initially, and with time is exchanged by another isoform (present in lower concentrations) that yields a more stable adsorbed layer. Comparing the adsorbed amounts with the calculated values for a monolayer (Table 1) indicated that during the peak an end-on monolayer was formed, but as competitive adsorption/spreading and/or reorientation occurred a relatively large part of the adsorbed proteins detached from the surface. Previous studies did not report any similar peaks in the adsorption behaviour of lactoperoxidase [22]. These contradictory results could be due to e.g. differences in the lactoperoxidase preparations used.

Fig. 3 illustrates typical initial adsorption kinetics during the first $5 \mathrm{~min}$ of adsorption of the proteins. The calculated values of the mass transport controlled adsorption rates for the proteins, using the diffusion coefficients given in Table 1, are inserted for comparison. For lactoferrin (Fig. 3a), the adsorption was diffusion controlled during the first $3 \mathrm{~min}$ on both types of surfaces, indicating that the initial adsorption was largely independent of surface type. Lactoperoxidase adsorption (Fig. 3b) showed to be diffusion controlled during the first $1.5 \mathrm{~min}$ of adsorption on both types of substrates. Previous observations on the initial rate of adsorption of lactoperoxidase in a phosphate buffer without added salt support these findings [22]. For lysozyme (Fig. 3c), the adsorption to hydrophobized silica was controlled by diffusion during the first minute. On hydrophilic silica, previous studies illustrated that the adsorption at low concentrations of lysozyme was diffusion limited in phosphate buffer without added $\mathrm{NaCl}$ up to $100 \mathrm{~s}$, while in phosphate buffer supplemented with $150 \mathrm{mM} \mathrm{NaCl}$, the adsorption was not diffusion controlled [24]. As seen in Fig. 3c, our data showed diffusion-controlled adsorption during the first $30 \mathrm{~s}$. For histatin 5 (Fig. 3d) the first $30 \mathrm{~s}$ of adsorption was diffusion controlled on both types of surfaces.

Deeper analysis of the initial adsorption showed that all the investigated proteins (except lysozyme on hydrophobized surfaces) deviated from their respective calculated mass transport adsorption rates at a surface coverage below $50 \%$ of plateau values. This indicates packing restrictions due to lateral forces 

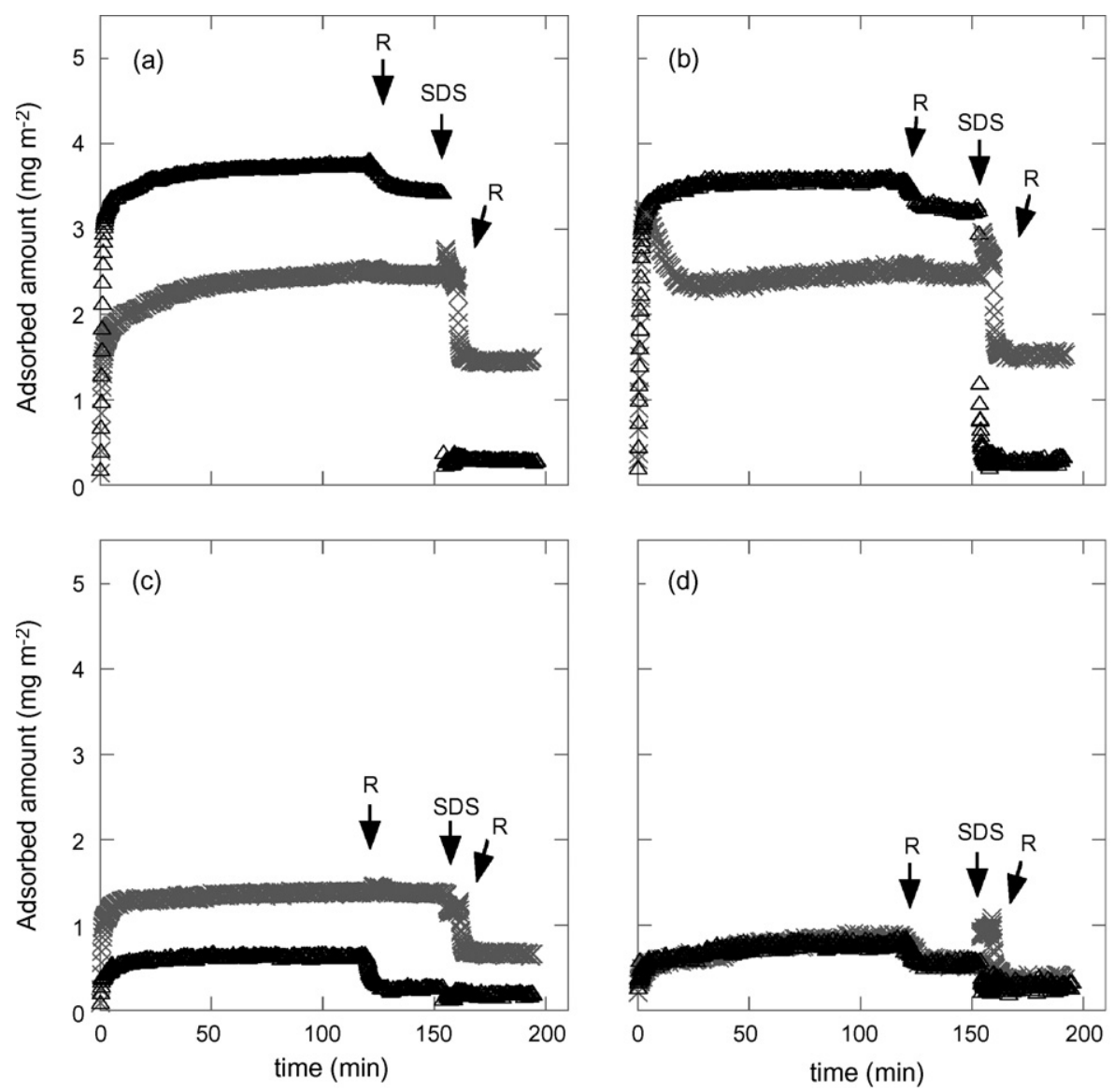

Fig. 2. Adsorbed amounts $\left(\mathrm{mg} \mathrm{m}^{-2}\right)$ vs. time ( $\mathrm{min}$ ) of $10 \mu \mathrm{g} \mathrm{ml}^{-1}$ solution of (a) lactoferrin, (b) lactoperoxidase, (c) lysozyme, and (d) histatin 5 on hydrophilic silica $(\triangle)$ and hydrophobized silica $(\times)$. Protein solutions were added at time $=0 . R=P B S$ rinsing, $S D S=$ addition of SDS.

between adsorbed proteins. Possibly, there is a slow deformation of the adsorbed proteins occurring at these low concentrations, leading to a larger surface area/molecule. At higher concentrations of the proteins (data not shown), the first few minutes of adsorption yielded higher adsorbed amounts in relation to the plateau values, indicating that as more proteins approached the surface simultaneously there is less time for any spreading to occur, leading to a smaller surface area per molecule and thus better packing on the surface.

For lysozyme on hydrophobized silica, the surface coverage when the adsorption deviated from the calculated diffusion rates corresponded to $80 \%$ of the plateau value, and no major differences were observed with increasing concentrations. This indicates that lysozyme does not undergo major conformational changes during adsorption.

\subsection{Elutability}

Many studies on the adsorption of protein solutions have shown that upon dilution, a fraction of the adsorbed amount is rinsed off, indicating multiple states of binding [20,41,44]. Further, previous studies on surfactant interactions with different types of in vitro formed salivary films on well-defined model substrates have illustrated different types of interactions [34,38,45]. The SDS concentration used in the present study $(17 \mathrm{mM})$ was well above the cmc in buffer (which is approximately $1.95 \mathrm{mM}$ ), and this SDS concentration has previously shown to completely desorb the in vitro salivary pellicle formed on hydrophilic silica from $10 \%$ human whole saliva [38].

On the hydrophilic silica, dilution and particularly addition of SDS influenced the adsorbed amounts of all investigated proteins (Fig. 2 and Table 2). PBS rinsing resulted in the removal of a fraction of loosely absorbed material, indicating multiple states of binding as mentioned above. Upon SDS elution, an immediate desorption was observed, which resulted in an almost complete removal of the adsorbed proteins. This effect was most evident for lactoferrin and lactoperoxidase due to their higher adsorbed amounts prior to addition of SDS (Fig. 2a and $b$ and Table 2). Previous studies on surfactant-protein interactions have described a mechanism for the elution [23], where SDS is believed to form charged complexes with the proteins on the surface. These complexes have a higher net negative charge and/or increased hydrophilicity, which result in increased electrostatic repulsion with the anionic surface and/or higher solubility. The complex formation seemed to be independent of adsorbed amounts of the investigated proteins prior to SDS addition, as the amount remaining adsorbed after SDS/PBS rinse was the same for all the proteins, at all concentrations (Table 2). This indicates that SDS was present in sufficient amounts for complex formations. Indeed, the cooperative binding of surfactant to proteins and 

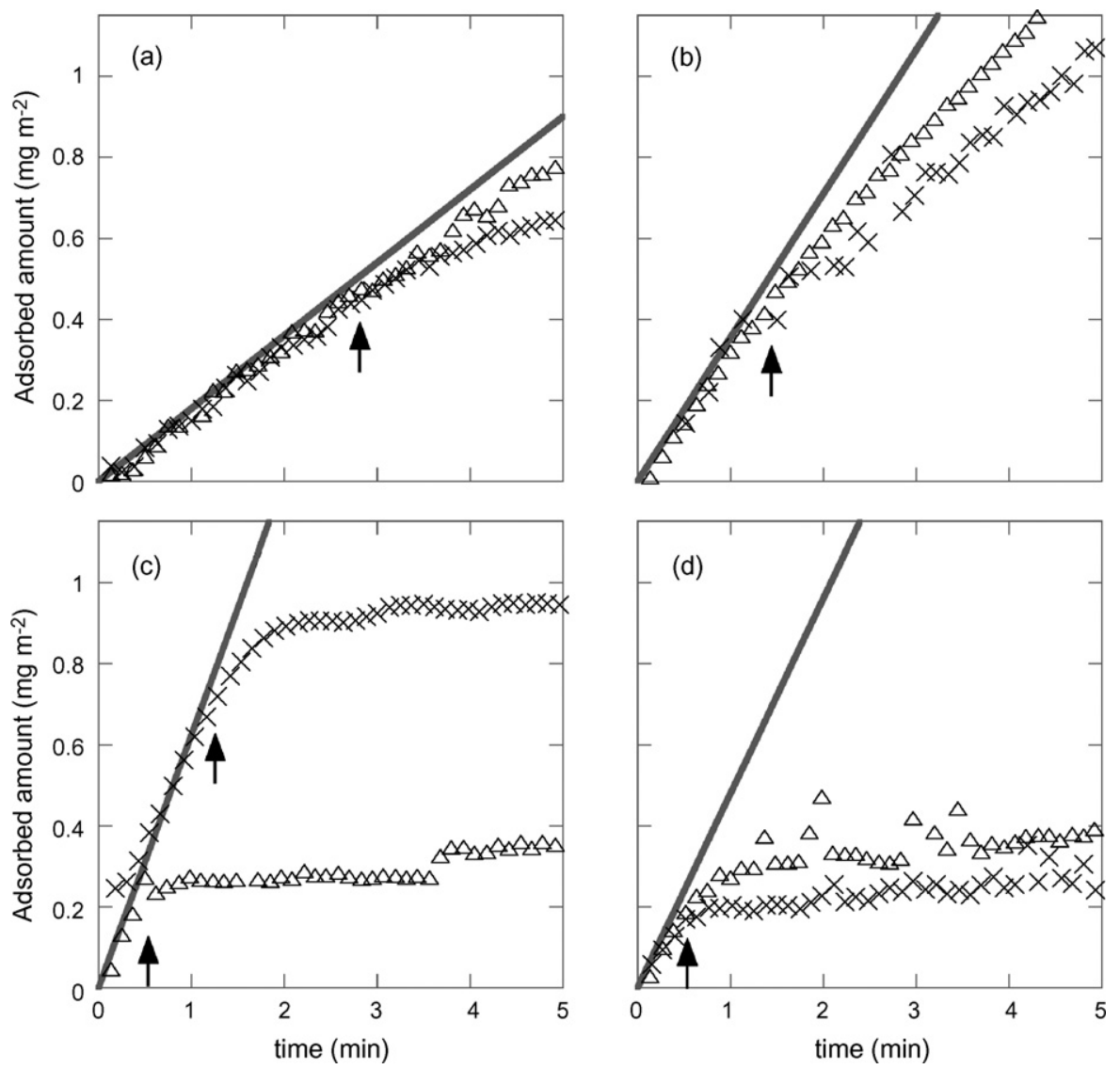

Fig. 3. Initially adsorbed amounts ( $\mathrm{mg} \mathrm{m}^{-2}$ ) vs. time (min) of (a) $1 \mu \mathrm{g} \mathrm{ml}^{-1}$ of lactoferrin, (b) $2 \mu \mathrm{g} \mathrm{ml}^{-1}$ of lactoperoxidase, (c) $2 \mu \mathrm{g} \mathrm{ml} \mathrm{l}^{-1}$ of lysozyme, and (d) $1 \mu \mathrm{g} \mathrm{ml}^{-1}$ of histatin 5 on hydrophilic silica $(\triangle)$ and hydrophobized silica $(\times)$. Theoretical adsorption rates for each protein, calculated from Eq. (4) for mass transport controlled adsorption are inserted in the respective graph for comparison (solid line). Arrows indicates where the adsorption starts to deviate from the theoretical adsorption rates.

polymers usually start at a critical association concentration lower than the cmc of the surfactant [46].

On hydrophobized silica, no desorption was observed upon dilution, rinsing with PBS, except for the case of histatin 5. This illustrates the strong binding strength of the hydrophobic interaction, which also may cause conformational changes due to the exposure of hydrophobic interior groups to the surface. Histatin 5, which is a small peptide, detached easily upon dilution, probably due to few surface contact sites per peptide. The generally higher adsorbed amounts that remained after SDS elution on hydrophobized silica surfaces in comparison to hydrophilic ones further illustrates a high degree of "irreversible" adsorption. Upon addition of SDS and during the $5 \mathrm{~min}$ when SDS was allowed to interact with the adsorbed protein films, only small changes in adsorbed amounts were observed for all proteins (Fig. 2). When buffer rinsing after SDS addition was initiated, a relatively large decrease in adsorbed amounts could be seen. A proposed mechanism for the SDS elution is that SDS coadsorbs to the protein film and exchanges part of the adsorbed proteins from the hydrophobized surface [23]. Complex formations between SDS and proteins are also expected, as described for hydrophilic silica. The SDS molecules are then desorbed during the following buffer rinse, leaving only the non-displaced fraction of proteins on the surface. This again indicates multi- ple states of protein binding. The remaining fraction seemed to be dependent on the protein size but also to some extent on the adsorbed amounts prior to SDS elution (Table 2).

The large fractions removed by SDS on both types of surfaces indicate that the combination of SDS-containing oral care products supplemented with one or more of these antimicrobial proteins could result in reduced efficiency, as pointed out by e.g. Tenovuo [47].

\subsection{Significance}

On hydrophilic silica surfaces the steep slopes of the isotherms and the high adsorbed amounts of the investigated proteins (correlating to side-on and end-on monolayer at concentrations relevant in saliva) suggests that these proteins have strong driving forces for adsorption, comparable to those observed for salivary secretions $[14,33,34,38]$ and single key-pellicle proteins [41,48].

Adsorption to oral interfaces may serve as a reservoir for the active antimicrobial components. The lower adsorbed amounts of lactoferrin and lactoperoxidase on hydrophobized silica indicates that dental materials with a more hydrophobic character, such as polymeric materials, will adsorb lower amounts of these proteins (which are less reversibly bound), which may have con- 
sequences for the depot of antimicrobial components formed in the oral cavity.

Further, more specifically for histatin 5, studies have shown that the candidacidal function is impaired upon adsorption, however when the peptides are desorbed the anti-Candida activity is reactivated $[10,11]$. This study showed that a large fraction of histatin 5 easily desorbed upon dilution, illustrating that the peptide might be readily released so that it can regain its antimicrobial activity. An additional advantage is that this may occur at its potential site of action that is e.g. at the denture/mucosa interface.

Finally, the effect of oral care products containing SDS may be two-fold; they may reduce the binding of the investigated proteins (and may also inactivate them [47]), but it may also increase the release of adsorbed proteins that are active in solution, such as histatin 5 .

\subsection{Summary}

To gain knowledge of the role of cationic protein adsorption in the pellicle formation, the adsorption of lactoferrin, lactoperoxidase, lysozyme and histatin 5 was investigated. Adsorption of the investigated proteins to the anionic hydrophilic silica surfaces showed to be dominated by electrostatic attraction. SDS elution resulted in immediate desorption which probably was a consequence of the formation of complexes between the proteins and SDS. On hydrophobized silica, the adsorption seemed to also be mediated by hydrophobic interactions (except for the case of histatin 5), which resulted in lower adsorbed amounts for lactoferrin and lactoperoxidase compared to hydrophilic silica, and the same adsorbed amounts for lysozyme and histatin 5. The proteins (excluding histatin 5) were more tightly bound to this surface type as indicated by buffer rinsing and SDS elution. Overall, the investigated proteins have shown to have a high surface activity within physiological concentrations and are therefore able to compete with anionic salivary proteins, thus indicating the possible importance of cationic proteins in the pellicle formation.

\section{Acknowledgements}

We are grateful to Dr. Stefan Welin-Klintström for preparing the oxidized silicone wafers. This study was supported by research grants from Malmö University, the Swedish Dental Society, the Swedish Patent Revenue Fund for Research in Preventive Dentistry and the Knowledge foundation (KK stiftelsen, Biofilms-research centre for biointerfaces).

\section{References}

[1] C. Dawes, G.N. Jenkins, C.H. Tonge, Br. Dent. J. 115 (1963) 65.

[2] U. Lendenmann, J. Grogan, F.G. Oppenheim, Adv. Dent. Res. 14 (2000) 22.

[3] A. van Nieuw Amerongen, J.G.M. Bolscher, E.C.I. Veerman, Caries Res. 38 (2004) 247.

[4] K.D. Kussendrager, A.C.M. van Hooijdonk, Br. J. Nutr. 84 (2000) S19.

[5] J.M. Steijns, A.C.M. van Hooijdonk, Br. J. Nutr. 84 (2000) S11.
[6] J. Tenovuo, in: J.O. Tenovuo (Ed.), Human Saliva: Clinical Chemistry and Microbiology, vol. 2, CRC Press, Boca Raton, FL, 1989, Chapter 2.

[7] J. Tenovuo, in: K.M. Pruitt, J. Tenovuo (Eds.), The Lactoperoxidase System-Chemistry and Biological Significance, Marcel Dekker, New York, 1985, Chapter 6.

[8] C. Hannig, J. Hoch, K. Becker, M. Hannig, T. Attin, Arch. Oral Biol. 50 (2005) 821.

[9] M. Edgerton, S.E. Koshlukova, Adv. Dent. Res. 14 (2000) 16.

[10] M. Edgerton, P.A. Raj, M.J. Levine, J. Biomed. Mater. Res. 29 (1995) 1277.

[11] A. Yin, H.C. Margolis, J. Grogan, Y. Yao, R.F. Troxler, F.G. Oppenheim, Arch. Oral Biol. 48 (2003) 361.

[12] Y. Yao, E.A. Berg, C.E. Costello, R.F. Troxler, F.G. Oppenheim, J. Biol. Chem. 278 (2003) 5300.

[13] P. Schupbach, F.G. Oppenheim, U. Lendenmann, M.S. Lamkin, Y. Yao, B. Guggenheim, Eur. J. Oral Sci. 109 (2001) 60.

[14] J.L. Jensen, M.S. Lamkin, F.G. Oppenheim, J. Dent. Res. 71 (1992) 1569.

[15] T. Sönju, G. Rölla, Caries Res. 7 (1973) 30.

[16] I. Iontcheva, F.G. Oppenheim, R.F. Troxler, J. Dent. Res. 76 (1997) 734.

[17] R.V. Soares, C.C. Siqueira, L.S. Bruno, F.G. Oppenheim, G.D. Offner, R.F. Troxler, J. Dent. Res. 82 (2003) 471.

[18] C. Wickström, C.E. Christersson, J.R. Davies, I. Carlstedt, Biochem. J. 351 (2000) 421.

[19] H. Gusman, C. Leone, E.J. Helmerhorst, M. Nunn, B. Flora, R.F. Troxler, F.G. Oppenheim, Arch. Oral Biol. 49 (2004) 11.

[20] M. Wahlgren, T. Arnebrant, M.A. Paulsson, J. Colloid Interf. Sci. 158 (1993) 46.

[21] J.R. Lu, S. Perumal, X. Zhao, F. Miano, V. Enea, R.R. Heenan, J. Penfold, Langmuir 21 (2005) 3354.

[22] J. Mårtensson, H. Arwin, I. Lundström, T. Ericson, J. Colloid Interf. Sci. 155 (1993) 30

[23] M. Wahlgren, T. Arnebrant, J. Colloid Interf. Sci. 142 (1991) 503.

[24] M. Wahlgren, T. Arnebrant, I. Lundström, J. Colloid Interf. Sci. 175 (1995) 506.

[25] T.J. Su, J.R. Lu, R.K. Thomas, Z.F. Cui, J. Penfold, J. Colloid Interf. Sci. 203 (1998) 419.

[26] J.R. Lu, T.J. Su, P.N. Thirtle, R.K. Thomas, A.R. Rennie, R. Cubitt, J. Colloid Interf. Sci. 206 (1998) 212.

[27] J. Buijs, V. Hlady, J. Colloid Interf. Sci. 190 (1997) 171.

[28] I. Rantanen, K. Jutila, I. Nicander, J. Tenovuo, E. Soderling, Swed. Dent. J. 27 (2003) 31.

[29] M. Malmsten, in: M. Malmsten (Ed.), Biopolymers at Interfaces, Marcel Dekker Inc., New York, 2003.

[30] P.A. Raj, M. Edgerton, M.J. Levine, J. Biol. Chem. 265 (1990) 3898.

[31] L. Stryer, in: L. Stryer (Ed.), Biochemistry, W.H. Freeman, New York, 1988.

[32] M. Wahlgren, T. Arnebrant, J. Colloid Interf. Sci. 136 (1990) 259.

[33] L. Lindh, T. Arnebrant, P.-E. Isberg, P.-O. Glantz, Biofouling 14 (1999) 189.

[34] I. Svendsen, T. Arnebrant, L. Lindh, Biofouling 20 (2004) 269.

[35] M. Malmsten, N. Burns, A. Veide, J. Colloid Interf. Sci. 204 (1998) 104.

[36] R.M.A. Azzam, N.M. Bashara, in: R.M.A. Azzam, N.M. Bashara (Eds.), Ellipsometry and Polarized Light, North Holland, Amsterdam, 1977.

[37] P.A. Cuypers, J.W. Corsel, M.P. Janssen, J.M. Kop, W.T. Hermens, H.C. Hemker, J. Biol. Chem. 258 (1983) 2426.

[38] I.C. Hahn Berg, U.M. Elofsson, A. Joiner, M. Malmsten, T. Arnebrant, Biofouling 17 (2001) 173

[39] H.J. Trurnit, Arch. Biochem. Biophys. 51 (1954) 176.

[40] J.M.M. Kop, J.W. Corsel, M.P. Janssen, P.A. Cuypers, W.T. Hermens, J. Phys. Colloq. C (Orsay, Fr.) 10 (1983) 491.

[41] L. Lindh, P.-O. Glantz, N. Strömberg, T. Arnebrant, Biofouling 18 (2002) 87.

[42] P.-O. Glantz, On Wettability and Adhesiveness, Department of Prosthetics, Faculty of Odontology, Lund University, 1969.

[43] M.E. Neiders, L. Weiss, T.L. Cudney, Arch. Oral Biol. 15 (1970) 135 . 
[44] T.A. Horbett, J.L. Brash, in: J.L. Brash, T.A. Horbett (Eds.), Proteins at Interfaces-Physicochemical and Biochemical Studies, American Chemical Society, Washington, DC, 1987, Chapter 1.

[45] N. Vassilakos, T. Arnebrant, P.-O. Glantz, Biofouling 5 (1992) 277.

[46] K.P. Ananthapadmanabhan, in: K.P. Ananthapadmanabhan, E.D. Goddard (Eds.), Interactions of Surfactants with Polymers and Proteins, CRC Press, Boca Raton, 1993, Chapter 8.

[47] J. Tenovuo, Oral Dis. 8 (2002) 23.
[48] M. Johnsson, M.J. Levine, G.H. Nancollas, Crit. Rev. Oral Biol. Med. 4 (1993) 371

[49] T. Imoto, L.N. Johnson, A.C.T. North, D.C. Philips, J.A. Rupley, in: P.D. Boyer (Ed.), The Enzymes, vol. 7, Academic Press, New York, 1972.

[50] A. Carlström, Acta Chem. Scand. 23 (1969) 185.

[51] C. Tanford, in: C. Tanford (Ed.), Physical Chemistry of Macromolecules, Wiley, New York, 1961. 